\title{
40 Years Experience of Romashkino Oil Field Development in Tatarstan: Improvements of Water Flooding
}

\author{
* Galeev R. G., * Muslimov R. Kh., * Diyashev R. N., **Blinov A. F. \\ * Tatnef, Russia \\ ** TatNIPIneft, Russia
}

\begin{abstract}
Copyright 1995. Steering Committee of the European IOR - Symposium.
This paper was presented at the 8th. European IOR - Sympositum in Vienna, Austria, May 15 - 17, 1995

This paper was selected for presentation by the Steering Committee, following review of information contained in an abstract submitted by the author(s). The paper, as presented has not been reviewed by the stearing committee.
\end{abstract}

\begin{abstract}
The system of contour water-flooding was for the first time introduced in Romashkino oil field, occupying the territory of about $4300 \mathrm{sq} . \mathrm{km}$. The field was divided into 21 independent areas of development by rows of injection wells. This allowed to bring into development the largest field by accelerated rates with reasonable economic costs. The following improvement of water-flooding system allowed to achieve oil recovery factor of $47.7 \%$ by the beginning of 1994 . Currently developed technological solutions for improvement of water flooding will allow to achieve oil recovery factor of about $53 \%$.
\end{abstract}

\section{Introduction}

Crude was discovered in the main oilsaturated Pashiyskian deposits of Devonian horizons in Romashkino field in 1948. Large sizes and complex geological structure of the field, limited financial resources and acute demand of the country for oil products during these years set the problem of creating new: system of development. It was suggested in 1950 by a group of specialists guided by academician A.P.Krylov. The introduction of the new system - contour flooding - began from 1952 on three central areas (Minnibaevskaya, Abdrakhmanovskaya, Pavlovskaya) with total area of about $70 \mathrm{sq} . \mathrm{km}$. This marked the beginning of the first in the world unique process of oil fields development. Its main principles were formulated in the 1-st general scheme (1956).

However, the following experience showed that not all statements of this project proved to be efficient. Therefore, subsequent improvement of the field development involved elaboration of the main principle - method of contour flooding. This process was submitted in 2-nd (1968) and 3-rd 
(1976) general schemes and is provided in 4-th general scheme being currently prepared.

\section{Geological Structure of the Field}

Romashkino oil field is a platform type multilayer one. Geologic cross-section of the field is formed by Devonian, Carbonian and Permian deposits of total thickness about $2000 \mathrm{~m}$. Of this value $75 \%$ accounts for carbonate and $25 \%$ for terrigenous rocks. Of 18 commercial oilbearing horizons, 7 horizons consist of terrigenous reservoirs, and 11 horizons - with carbonate ones.

As for tectonics, the oil field coincides with southern dome of Tatarian arch, which presents a large rounded uplift with steep western and southern and relatively gentle northern and eastern slopes. The surface is poorly rugged, the amplitude of some uplifts does not exceed 20 m (Figs 1,2).

Oil pools of Pashiyskian D1 and Kynovskian D0 horizons are mainly exploited in the field, this makes $88.8 \%$ of all explored reserves of the field. Total area of oil saturated reservoir is about 4300 sq. $\mathrm{km}$.

Permeable layers in horizons DI and D0 are fine-grained sandstones, coarsegrained aleurolites and their combination. Their granulometric composition is homogeneous. Median size of grains for sandstones is within $0.1-0.2 \mathrm{~mm}$, for aleurolites it makes $0.05-0.1 \mathrm{~mm}$. Fragmental clays serve as primary cementing agent in sandstones. Their content is not more than 3-5\%. The most widespread cement is secondary quartz. which is severely corroded in oil-bearing rocks. Total content of this cement on the average makes $1-5 \%$.

All formations are divided into three groups of rocks:

- first - high permeable zones,

- second - low permeable zones,

- third - non-permeable zones.

First group includes high productive reservoirs of permeability more than 0.1 $\mathrm{mkm} 2$. There are 2 classes of rocks in this group: high productive non-clay rocks (clay content not more than $2 \%$ ) and high productive clay rocks (clay content more than $2 \%$ ).

Second group includes reservoirs of permeability from 0.03 to $0.1 \mathrm{mkm} 2$.

Third group includes reservoirs of permeability less than $0.03 \mathrm{mkm} 2$ (relative permeability less than $0.01 \mathrm{mkm} 2$ ) and clays, i.e. a group of non-reservoirs.

Total thickness of Pashiyskian hortizon DI deposits varies from 15-20 to $50 \mathrm{~m}$ and more. In cross-section of the horizon up to 9 layers of reservoirs are determined, thickness being from 1-2 to 3$6 \mathrm{~m}$, separated from each other by clay rocks.

The layers are marked downwards: $a, b l$ b2, b3, v, g1, g2, g3, d. Producing layers of horizon DI constitute a single hydrodynamic system, total oil-water contact is at elevation $-1490 \mathrm{~m}$. The whole section is present on central areas of the field, on periphery only upper layers are oil-bearing ones (Figs 2,3).

The upper layer $a$ in the north of the field has an areal extension. Layers bl, b2, b3 are mainly lenticular ones, on some areas they rather often merge with each other forming zones of merging with meridional direction. Layer $v$ is less lenticular compared with layers of group b but on some areas one can observe zones with worsened reservoir properties and its replacement for non-permeable ones. Lower layers g, d, if not divided into separate interlayers, have areal extension.

Producing deposits of layer D0 are characterized by areal banded occurrence of mainly latitudinal trend. Up to three interlayers are determined in the layer, total thickness up to $4 \mathrm{~m}$. Layer Do lies in the middle part of Kynovskian horizon and is located predominantly in the north-west of the field.

The average value of oil saturation layers D1, D0 varies from $70 \%$ on periphery to $90 \%$ in the centre of the field. Oil saturation varies throughout the section upwards from 0.83 in layer gd to 0.79 in layer a.

\section{Concept of the Field Development Using the Method of Contour Water-Flooding and Its Progress}


The concept of Romashkino field development had to meet the following requirements:

- putting of the field on commercial production prior to completion of its contouring;

- beginning of the field development from its most productive, arch part;

- subsequent accelerated bringing into production of peripheral areas, providing simultaneous efficient exploitation of the whole field;

- provision of high oil recovery of the field, considerably exceeding maximum value achieved by this period.

Only essentially new system of development could meet these requirements involving maintenance of formation pressure by water injection into rows of injection wells located within oil pool outline. The field was recommended to divide by rows of injection wells into separate independent areas. Oil displacement by water in this situation occurs in both directions from injection row, the opportunity appears to bring into development, in the first place, central most productive areas of the field. For the short period and with relatively low capital investments, considerable increase of production is achieved and further maintenance of oil recovery rates is provided during a long period.

Main principles of the new system were formulated in the first general scheme of Romashkino field development (1956):

1. The oil pool of horizon D1 (horizon Do in the scheme was not considered) is divided into 21 areas by rows of injection wells (Fig.4).

2. Dividing lines are located along oil pool outlines in some layers, on areas with sufficiently good reservoir properties of formations, in points of most structural low. The width of the "cut" areas is established within $6-13 \mathrm{~km}$ with consideration of the extent of inhabited area.

3. Each one of the areas is put on production according to individual project, where a rational well pattern is substantiated (within 24-52 ha and increasing with the decrease of producing horizon thickness).
4. Three rows of producing wells are drilled in parallel to each injection row at the first stage. Central part is put into operation upon water flooding of the first, second, etc. rows. Shutting-in of wells is performed with $50 \%$ water-cutting.

5. With the aim of increasing the efficiency of injection, provision is made for transfer of injection front to watercut producing wells.

6. To increase water-free oil production period between injection row and first row of producing wells, a double distance is accepted between producing rows (up to $2000 \mathrm{~m}$ ).

7. Provision is made for $30 \%$ reserve of producing wells of their initial number for densening of well pattern on areas which are not involved in development.

8. All layers of horizon D1 are developed by one system of producing and injection wells. Every second well is completed for water. injection. Intermediate wells actively operate for oil up to $50 \%$ of water-cutting and after that they are also converted for injection.

9. At the first stage combined water injection into all layers is performed. On some areas transfer to simultaneous-selective water injection is necessarily implemented under different injection pressure.

10. Formation pressure on dividing lines is maintained on the initial level, i.e. $17.5 \mathrm{MPa}$.

11. Average pressure on bottom holes of producing wells is established on the level of flowing pressure, i.e. 12.5 MPa.

Optimum level of oil production was determined, to be achieved in 1965. Separate area levels were estimated on the basis of the whole field oil production. Ultimate oil recovery was estimated to be about $60 \%$ of initial geological reserves.

The subsequent process of development of separate areas and the whole field proved the truth of the first general scheme statements.

However, mass investigation of wells using downhole flowmeters showed that about $50 \%$ of formations when they are perforated simultaneously, do not take part in production. Uniform well spacing density for each area proved to be ineffective under the conditions of 
significant areal heterogeneity of formations, the technology of simultaneous-selective production and injection did not justify itself because of reciprocal influence of layers. Wide zones between injection-row and first producing row were also a failure.

Multistage system of development proved to be completely ineffective, it included shutting-in of producing well rows with achievement of $50 \%$ water-cut and transfer of injection row upon beginning of water flooding of second wells row, densening of wells pattern in central part of the area in a zone of contraction of oil displacement outlines $[1,2]$.

Second general scheme of development (1968) eliminated some shortcomings in the field development. The following basic statements were submitted in the scheme:

1. Decrease of zones width on separate areas to $5-6 \mathrm{~km}$.

2. Arrangement of 5 rows of producing wells between two injection rows.

3. Limiting the distance between injection line and first row of producing wells to $1200 \mathrm{~m}$ and on marginal areas with low permeability and sharp heterogeneity of reservoirs - to a value equal to a distance between producing rows.

4. Shutting-in of wells of first producing rows with $90 \%$ water-cut, and contracting rows - with achievement of profitability limits.

5. Transfer of injection front on flooded-out areas with the aim of increasing oil recovery and stimulation of wells operation.

6. Increase of formation pressure on injection line above initial one.

7. Decrease of bottom-hole pressure in producing wells to saturation pressure.

8. Restricted application of the method of simultaneous-selective injection and production.

9. Introduction of spot water flooding on areas not involved in flooding on the injection rows side.

10. Application of selectiive water flooding system on highly heterogeneous areas with interrupted structure of formations.

Second general scheme provided introduction of layers DO into development.

Subsequent analysis showed that the second general scheme has been prepared without consideration of the influence of wells pattern density on oil recovery. Indeed, the designed stock of wells has increased by $28 \%$, while oil area by that period has increased by $36 \%$, i.e. finite well pattern density has decreased by $6 \%$. As a result, as of January 1, 1976, 15.6\% of original oil-in-place reserves proved to be not involved in active production, and $73.4 \%$ of reserves of low permeable formations and oil-water zones were produced at low rates. The problem of producing formations subdivision was not also substantiated. This required further improvement of the field development principles, which was realized in the third general scheme (1976), providing the following:

1. Selective densening of wells pattern.

2. Bringing of the ratio of injection wells to producing ones to $1: 3$.

3. Organization on central areas of independent water flooding system for upper formations member.

4. Application of optimal pressure drops, considering geological-physical factors of formations under development.

5. Timely isolation of flooded formations.

6. Application of physical-chemical methods of enhanced oil recovery: in-situ sulphurization or injection of surfactants was provided practically in all newly put in operation injection wells.

7. Application of selective water flooding system for development of reserves in oil-water zone.

8. Involvement into production of low permeable reservoirs at the expense of spot and selective water flooding and increasing necessarily injection pressure to vertical rock pressure of $0.85-0.95$.

9. Decrease of bottom-hole pressure in water-free wells by $20-25 \%$ lower than saturation pressure.

10. Isolation of flooded formation with achievment of economically allowable ultimate water-cut (the higher 
formation productivity, the higher is percentage when isolation is performed).

Dynamics of changing main indices of development of horizons D1, D0 is shown in Fig.5.The analysis of the figure does not allow to single out the details showing the process of improvement of the field development system. However, the following important statements can be noted:

- maximum oil production level $2.1 \%$ of geological reserves was achieved in 15-16 years upon putting the field on production. The production on this level continued for 8 years.

- active water-cutting of well product began in 10 years of the field exploitation and continued for 23 years. Since 1985 the water-cut is being kept on a stable level of $87 \%$.

- during the whole period of the field exploitation a stable process of infill drilling continues aimed at improvement of the field development.

Indeed, each area has its peculiarities depending on geological structure and accepted design solutions for its development. The process of improvement of water flooding system had also some peculiarities. However, above mentioned basic statements, included in general scheme of the field development, were for the most part realized. Some characteristic data of separate areas development are submitted in the table. (Fig.4, Fig.6) illustrate dynamics of water flooding system progress for Abdrakhmanovskaya area.

\section{Hydrodynamic and Physical- Chemical Methods of Enhanced Oil Recovery}

$\begin{array}{lcrr}\text { Development } & \text { of } & \text { water } & \text { flooding } \\ \text { methods } & \text { means } & \text { in } & \text { essence }\end{array}$ hydrodynamic methods of enhanced oil recovery. Of the above mentioned trends the following can be referred to these methods: subdivision of producing formations, optimization of wells pattern density, change of producing and injection wells ratio, optimization of bottom-hole injection and production pressure, introduction of spot and selective water flooding systems, etc.

Special place in development of heterogeneous formations at present is assigned to non-stationary cyclic waterflooding, which is usually combined with change of fluid filtration flows information [3].

With consideration of technical support possibilities, different modifications of cyclic influence are used. These include mainly alternate cease of water injection by groups of wells in succession and whole rows of wells in different options, with duration of halfcycle from 10-30 days to 1-6 months, as well as cease of injection for longer period (about-1-year). About tens schemes of cyclic influence conductance with change of filtration flows direction have been developed (Fig.7).

Currently $72 \%$ of wells operate under cyclic water-flooding. To control waterflooding process, volumes of injection on some areas are limited (about 1000 wells are shut in, the formations in 6500 wells are isolated, about 2000 wells operate under limited production conditions), on other areas- with the aim of intensifying the process - the injection volumes are increased using different methods of treatment of bottom-hole zones. Restriction of associated water production is performed by shut-in of noncommercial highly water-cut wells (3870 wells are shut in), isolation of flooded formations (in 3560 wells), stimulation of oil recovery in water-free or low watercut régions, oil displacement from partially flooded-out formations or oilwater zones into oil zones, by special operating conditions of water-cut wells on highly flooded regions.

Due to wide applicatioon of hydrodynamic methods of improved oil recoovery (IOR), control and regulation of development processes, about $40 \%$ of the total volume is produced annually in the field.

Improvement of hydrodynamic methods implies hydraulic fracturing of formation (for the period of 1992-1993 in Romashkino field 82 hydrofracs were performed, production increased by 2.5 times), improvement of well completion 
while drilling (increase of production rate by 2-3 imes) and after casing without perforators or using drilling perforator DP-112, drilling of horizontal wells or horizontal bore-holes from old vertical wells $^{-}$(increase of production rate by about 5 times), forced fluid recovery, etc.

History of application of physicalchemical EOR methods in Romashkino field numbers more than 20 years. Almost all known in Former Soviet Union and world practice EOR methods were introduced or passed commercial tests. Practically in every fifth injection well were injected some reagents for increasing oil production.

So far as in Romashkino field different methods of water flooding are used on a large scale from the very beginning of the development, all EOR methods are intended for improvement of the field development data exactly by water flooding method. Therefore, recommended technologies for enhancing oil recovery shall be consistent with the well established water flooding system in the field.

The second peculiarity of using physical-chemical EOR methods as tertiary methods of influence on formation is that they are used under established system of development. It means that if organization of common water-flooding meets with failure, then upgrading of water by addition of chemical reagents will not essentially remedy the situation. Therefore, the most important task remains, in the first place, improvement of water-flooding methods. Tertiary methods - chemical additives, being introduced in the field, are aimed at improvement of water flooding data. either by increase of oil-displacement properties of injected water (watersoluble surfactants), or by increase of sweep efficiency (polyacrylamide, cellulose ethers). Synergistic effect is obtained with complex application of different purpose chemical additives (alkylated sulfuric acid, trisodium phosphate. oil-soluble surfactants).

For the whole period of Romashkino field development more than 20 different chemical EOR methods passed tests and were used on a commercial scale.
However, additional oil production during this period made up not more than $1 \%$ of total production. Maximum additional oil production in the amount of $1.4 \mathrm{mln}$ tons was achieved in 1989 . Operations for injection of chemical additives were performed on 1500 patterns including 7000 wells. Maximum oil production was obtained due to injection of sulfuric acid and surfactants (79\%), less volumes were obtained at the expense of injectioon of trisodium phosphate, alumina sulphate, water-soluble polymers, polymer-dispersing systems, cellulose ethers.

A complex of technologies for improvement of water-flooding methods and control of development process allowed to reduce production of associated water by $55 \%$. Accordingly, water injection decreased, and technicaleconomic indices of development improved.In production of about $47.7 \%$ of geologic reserves, water-oil ratio made up 1.4 in total. Results of estimation prove the possibility to complete the development of the field with oil recovery factor of $53 \%$ and water-oil ratio of 3.0 3.5.

Experience shows that at late stage the following two main problems should be solved in Romashkino field: to provide most complete production of waterflooded active oil reserves and introduce hard recoverable reserves into efficient production. The first problem is solved by systematic control and regulation of development processes using mainly hydrodynamic EOR methods, the second one - by introduction of non-drained reserves with further optimization of producing formations size, well patterns, water-flooding systems, formation and bottom-hole pressures. Volumes of introduction of all these methods will be considered in being currently prepared 4-th general scheme of Romashkino field development.

\section{Conclusion}

1. A new system of contour water flooding was introduced for the first time in the world in the major Romashkino oil field. It allowed to provide production of 
considerable volumes of oil in the shortest time and with limited resources.

2. The contour water flooding system during more than 40 years of the field development is continuously improving as for well patterns and pattern density, ratio of injection and producing wells, composition of producing formations and injection pressure, isolation and additional perforation of formations, etc.

3. Contour water flooding method was significantly improved using nonstationary influence and change of filtfration flows which provided increase of both current and ultimate oil recovery factors.

4. Chemical additives to water for enhancing oil recovery, despite large volumes of introduction, provided slight additional oil production (about $1 \%$ of total production). This confirms that they play an auxiliary role only in realization of powerful method of contour waterflooding in Romashkino field.

5. Current state of the field development is characterized by high water-cut of product, increase of the share of hard recoverable oil reserves, etc. However, accumulated experience and wide complex of hydrodynamic methods of enhancing oil recovery allows to predict ultimate oil recovery factor being not less than $53 \%$.

\section{References}

I. R.Kh.Muslimov. "Influence of geological structure peculiarities on efficiency of Romashkino field development". Kazan. KGU, 1979, p.212 (in Russian).

$2 . \quad$ R.N.Diyashev. "Combined development of oil formations." Moscow. Nedra, 1984, p.208 (in Russian).

3. R.Kh.Muslimov, A.F.Blinov, A.M.Shavaliev. "Hydrodynamic methods for control of development process, used at late development stage of Tatarstan oil fields." Neftepromyslovoye Delo, 1993,6-7, p.50-57 (in Russian). 
Table - Main development data of Romashkino field and separate areas

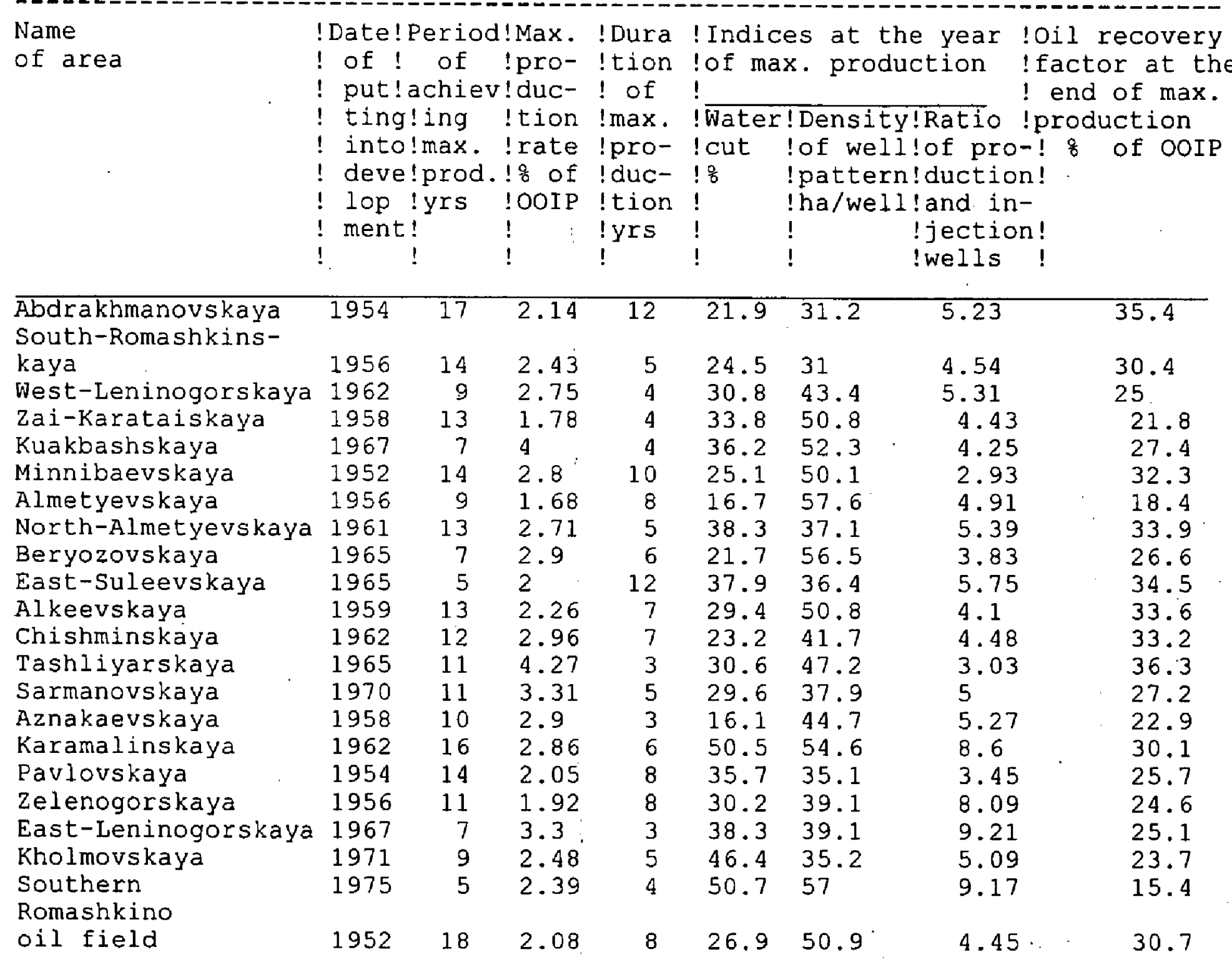




\section{Fig.1. Tatarstan. Sketch map of oil fields.}

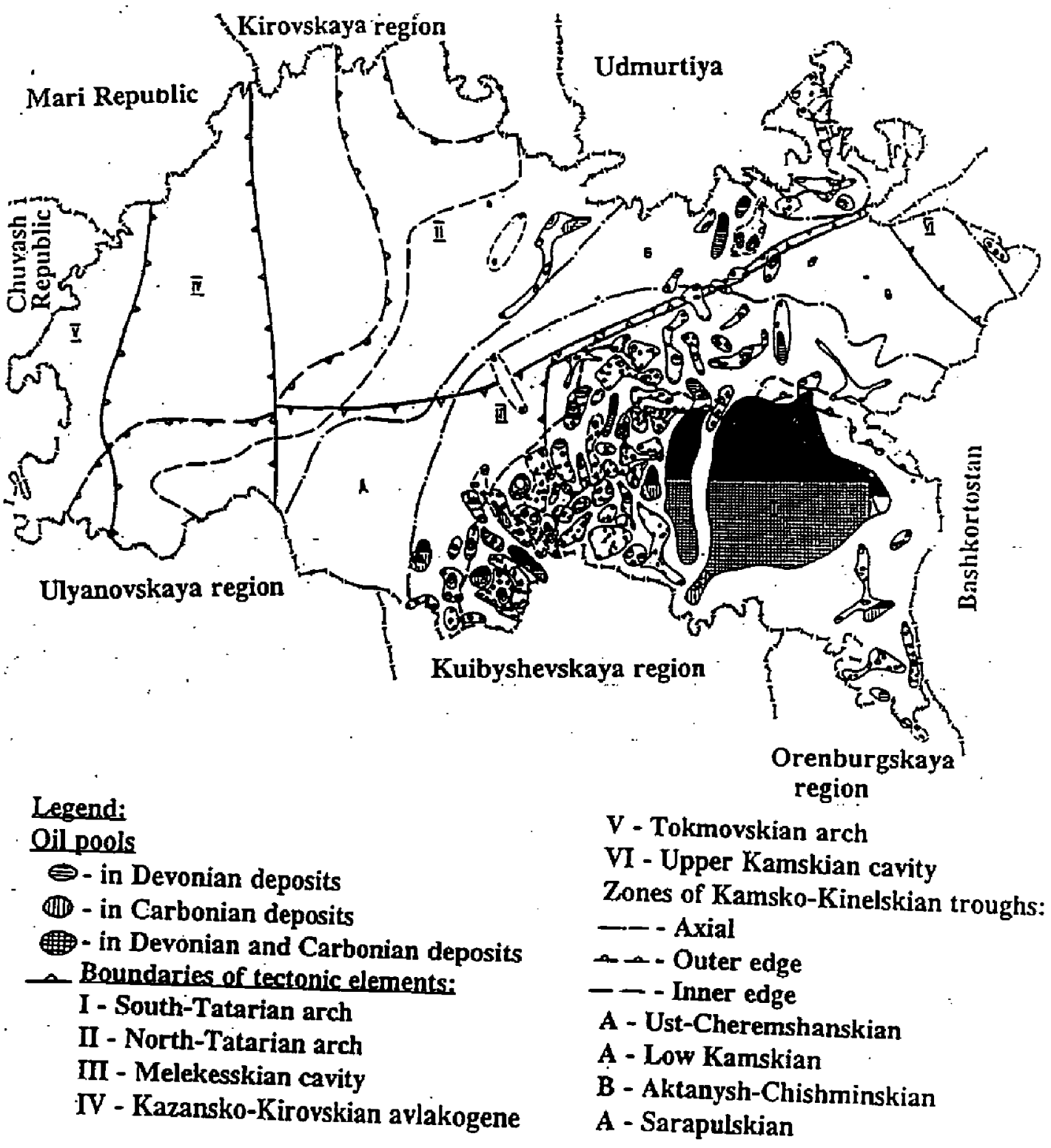

Fig.2. Geologic cross-section of Romashkino oil field.

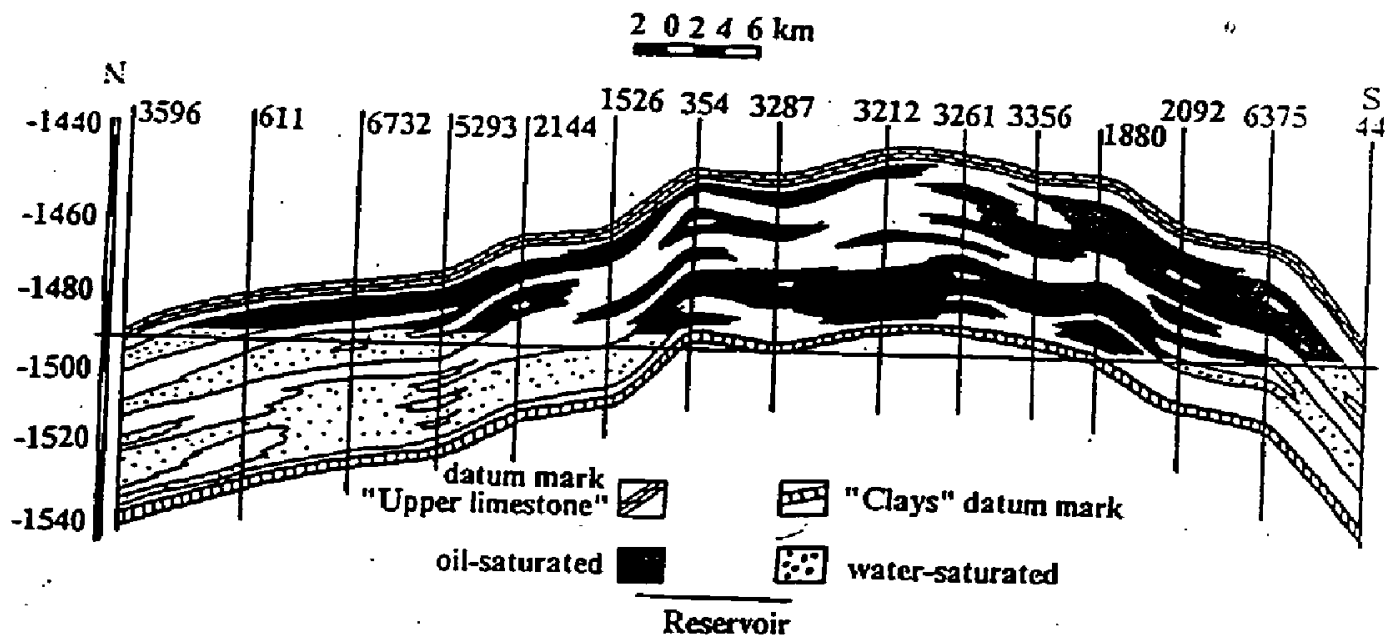


Fig.3. Cross section. Part of Romashkino oil field.

$500 \quad 0 \quad 500 \quad 1000 \mathrm{~m}$

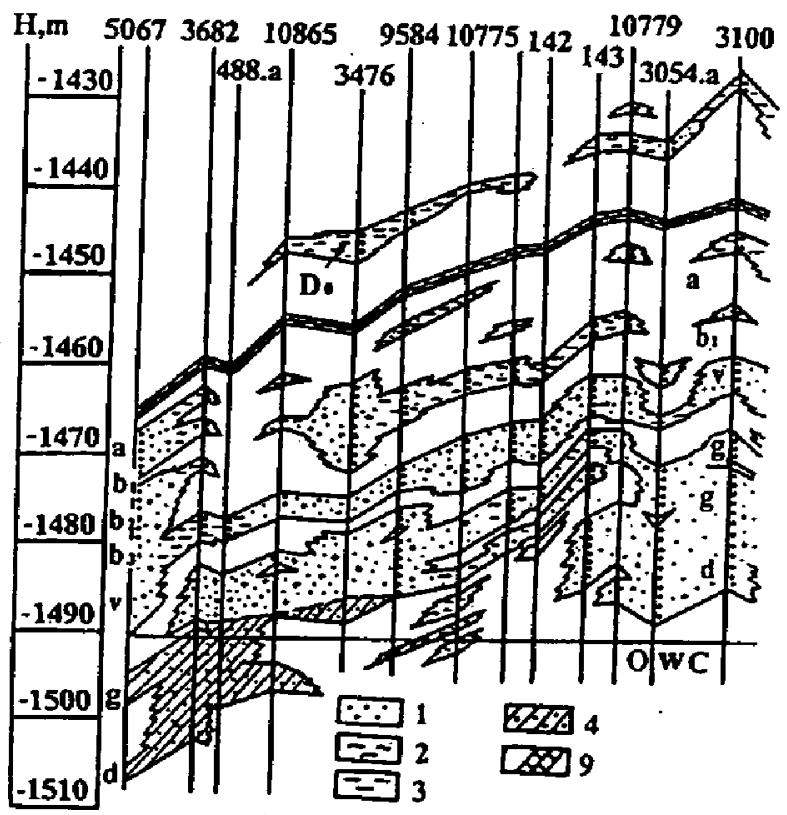

Legend: Loyers: oil and gas-saturated, 1 group:

1 - 1 subgroup; 2 - 11 subgroup; 3 -11 group; 4- water-saturated; 9 - upper limestone
Fig.4. Diagram of water flooding system on Romashkinskaya oil field (a) and its development on Abdrakhmanovskaya area (b).
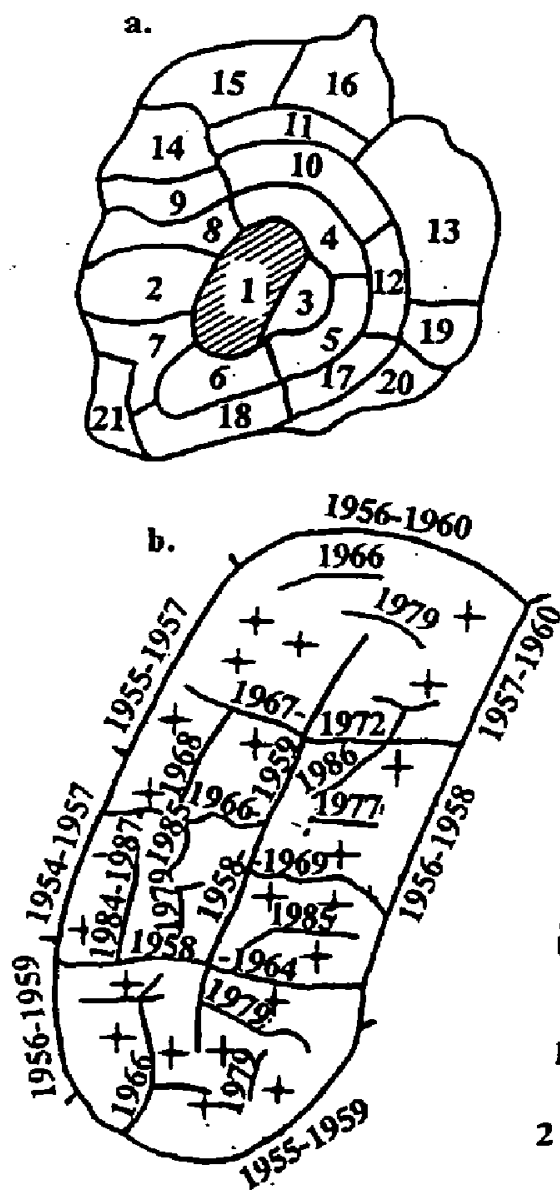

1-Abdrakhmanovskaya

2-Minnibaevskaya

3-Pavlovskaya

4-East-Suleevskaya

5-Zelenogorskaya

6-South-Romashkinskaya

7-Zai-Karataiskaya

8-Almetyevskaya

9-North-Almetyenskaya

10-Alkeevikaya

11-Chishminskaya

12-Kholmovskaya

13-A2nakaevskaya

14-Beryozovskaya

15-Sarmanovskaya

16-Tashliyarskaya

17-East-Leninogorskaya

18-West-Leninogorskaya

19-Karamalinskaya

20-Southern

21-Kuakbashskaya

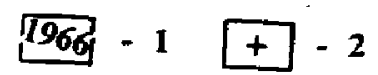

1 - row of injection wells; spud date

2 - injection spot wells 
Fig.5 Romashkino field

Main development indices

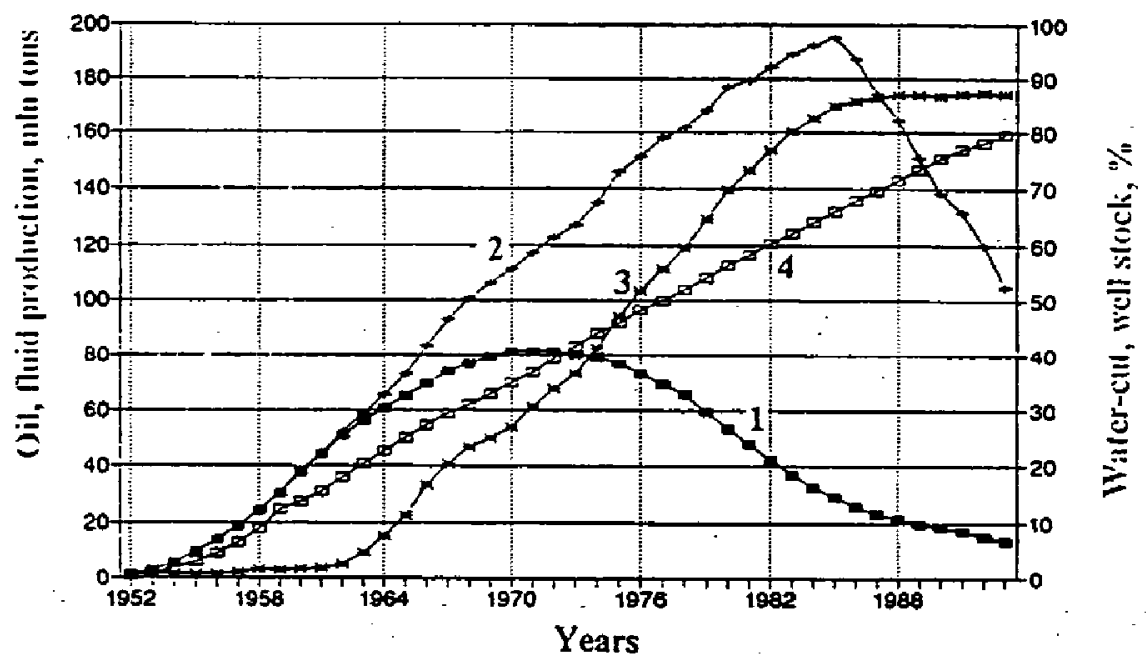

1 - oil; 2 - fluid; 3 - water cut; 4 - number of wells;

Fig.6. AREA OF ROMASHKINO OIL FIELD $(30.2 \mathrm{~km} 2)$ : INFILL DRILLING
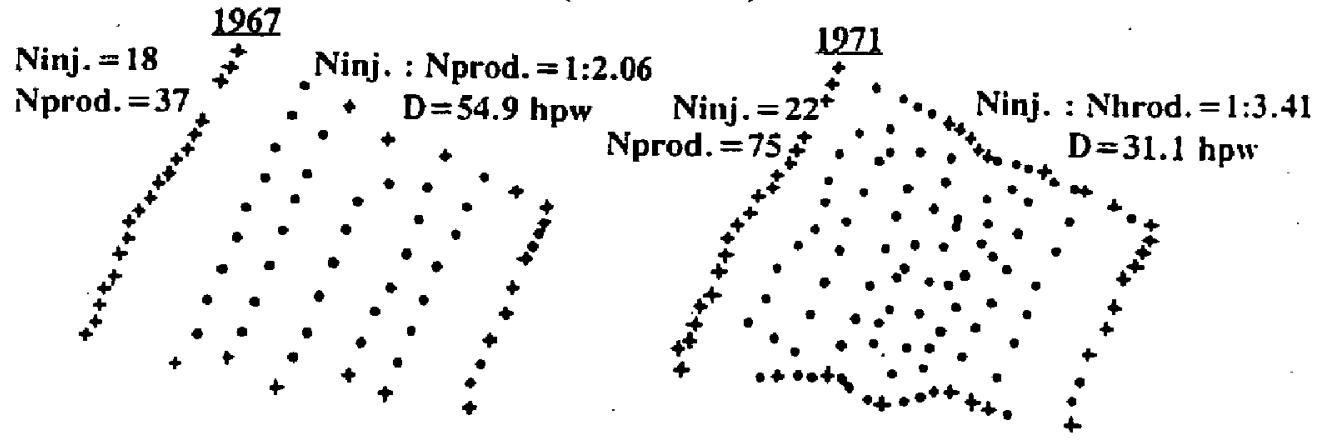

Ninj. =38 $\stackrel{1979}{+}$ Ninj. : Nprod. = 1:3.74 Ninj. $=79+\frac{1988}{+}:$ Ninj. : Nprod. =1:1.65 prod. $=104+\because+t_{+}^{+} \mathrm{t}=21.3 \mathrm{hpw}$ Nhrod. $=130_{+}^{+}+t_{t+t_{+}} \quad \mathrm{D}=14.4 \mathrm{hpw}$
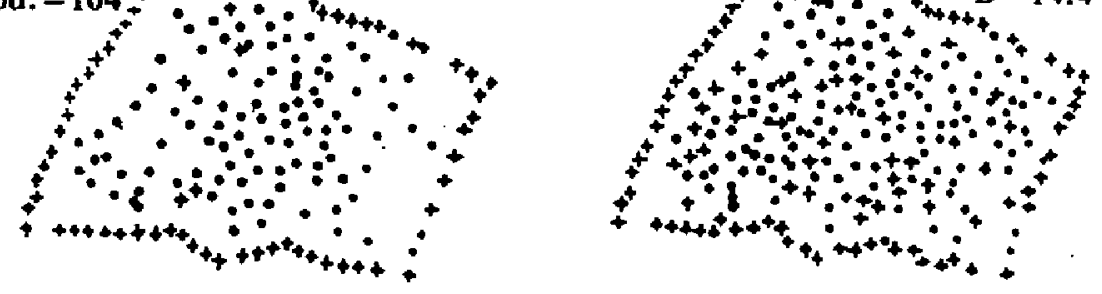
Fig.7. Scheme of cyclic water-flooding with change of filtration flows direction
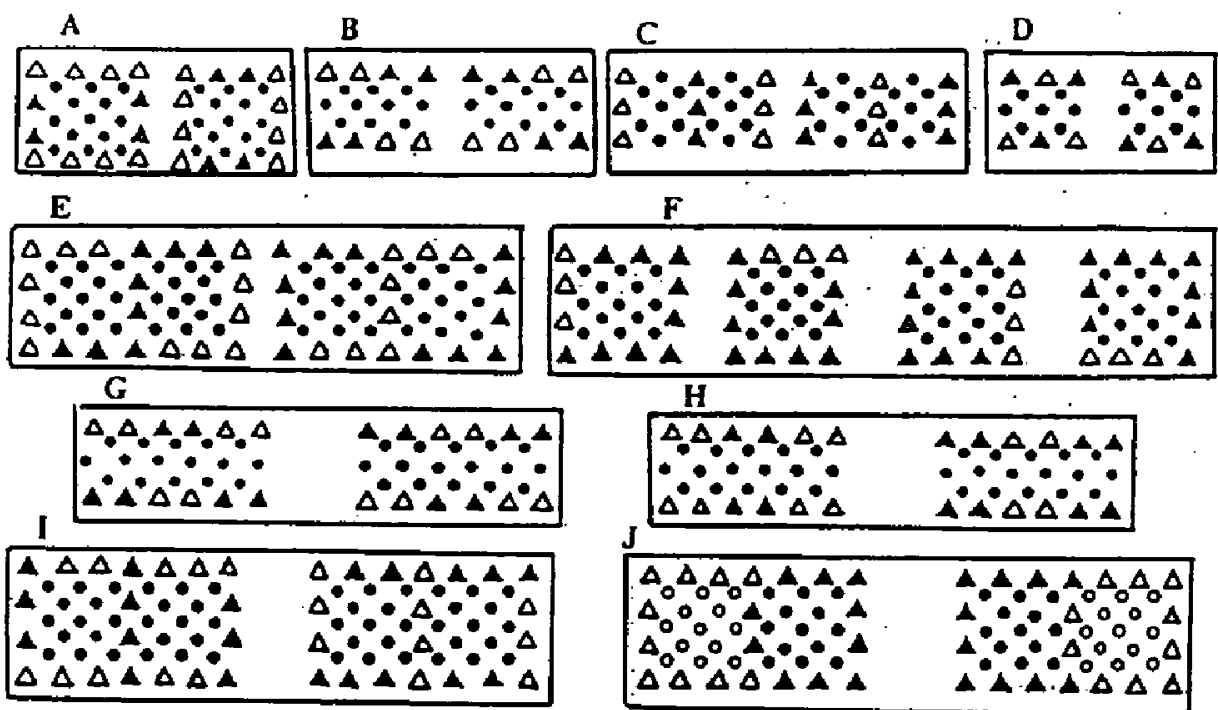

$\mathbf{F}$
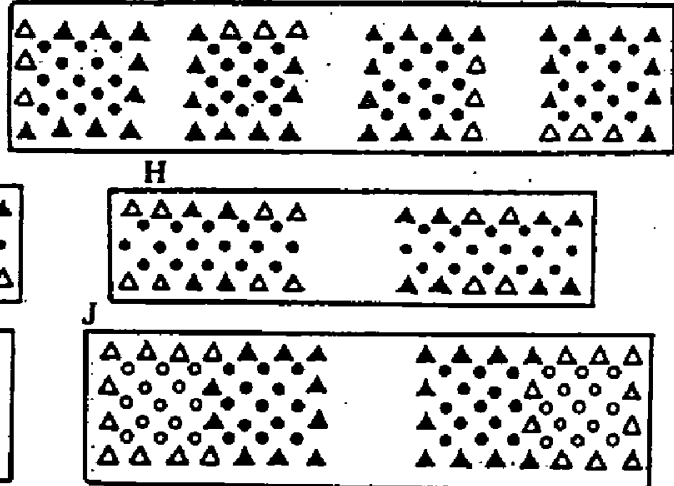

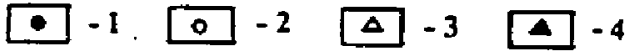

Legend:

A-conventional;

B-crossed

C-every second row;

Devery second well in a row,

E-block-angle;
F-circurlar;

G-sinusoidal;

H-by rows, line-alternating;

1-block-pattern;

J-block, aiternation of injection and production

Producing well: 1-in operation; 2-shut-in;

Injection well:3-in operation; ' 4-shut-in; 